\title{
Numerical Simulation Analysis of Unfilled and Filled Reinforced Polypropylene on Thin-Walled Parts Formed Using the Injection-Moulding Process
}

\author{
M. D. Azaman, ${ }^{1,2}$ S. M. Sapuan, ${ }^{1,3}$ S. Sulaiman, ${ }^{1}$ E. S. Zainudin, ${ }^{1,3}$ and A. Khalina ${ }^{4,5}$ \\ ${ }^{1}$ Department of Mechanical and Manufacturing Engineering, Universiti Putra Malaysia (UPM), 43400 Serdang, Selangor, Malaysia \\ ${ }^{2}$ School of Manufacturing Engineering, Universiti Malaysia Perlis, 02600 Arau, Perlis, Malaysia \\ ${ }^{3}$ Laboratory of Biocomposite Technology, Institute of Tropical Forestry and Forest Products (INTROP), \\ Universiti Putra Malaysia (UPM), 43400 Serdang, Selangor, Malaysia \\ ${ }^{4}$ Department of Biological and Agricultural Engineering, Universiti Putra Malaysia (UPM), 43400 Serdang, Selangor, Malaysia \\ ${ }^{5}$ Aerospace Malaysia Innovation Center, Universiti Putra Malaysia (UPM), 43400 Serdang, Selangor, Malaysia
}

Correspondence should be addressed to S. M. Sapuan; sapuan@upm.edu.my

Received 31 December 2014; Revised 8 March 2015; Accepted 8 March 2015

Academic Editor: Mahbub Hasan

Copyright (C) 2015 M. D. Azaman et al. This is an open access article distributed under the Creative Commons Attribution License, which permits unrestricted use, distribution, and reproduction in any medium, provided the original work is properly cited.

Thin-walled moulding technology has attracted increasing attention, particularly in electronic packing applications. The injection moulding of shallow, thin-walled parts with a thickness of $0.7 \mathrm{~mm}$ was performed using three types of materials from polypropylene, PP (PP, PP $+50 \mathrm{wt} \%$ wood composite, and PP $+10 \mathrm{wt} \%$ glass fibre composite). The highest deflection resulting from PP $+50 \mathrm{wt} \%$ wood does not occur in the critical area of the thin-walled part compared with PP $+10 \mathrm{wt} \%$ glass fibre. In addition, the results revealed that the warpage at the midpoint of the part surface injected using PP $+50 \mathrm{wt} \%$ wood is $0.04 \mathrm{~mm}$ lower than the value of $0.08 \mathrm{~mm}$ obtained when injected using PP $+10 \mathrm{wt} \%$ glass fibre. The warpage was hypothesised to result from the residual stress caused by nonuniform volumetric shrinkages formed during the solidification phase.

\section{Introduction}

Recently, the thin-walled moulding technology has attracted increasing attention for some applications specifically in electronic packaging. These industries tend towards the production of products that possess characteristics such as thinness, light weights, small dimensions, environmental friendliness, and good structural strength. Therefore, manufacturer concerns regarding the research and development of creating $3 \mathrm{C}$ (computer, communication, and consumer) products indicate that the products should have the properties such as light weights, thinness, short lengths, and small dimensions. In 2014, some companies, such as Roctool, Ju Teng, and Xiomi Inc., demonstrated the capability of producing thin-walled electronic housings for smartphones and tablets with thicknesses of less than $1 \mathrm{~mm}[1,2]$.

Shen et al. [3] investigated the optimum number of gates used during the filling stage by taking into account the moulding conditions. The analysed geometrical model was a battery cover with a wall thickness at the four sides of $1.0 \mathrm{~mm}$ and a thickness at the base central region of $0.2 \mathrm{~mm}$. Ozcelik and Sonat [4] also investigated the optimisation of the warpage and structural strength of a cell phone cover measuring $0.9 \mathrm{~mm}, 1 \mathrm{~mm}$, and $1.1 \mathrm{~mm}$ in thickness using carbon fibre-reinforced PC/ABS composite materials. Azaman et al. [5-7] demonstrated that the lignocellulosic polymer composite is suitable for moulding thin-walled parts with thicknesses of $0.7 \mathrm{~mm}$, as confirmed via simulation analysis using the MoldFlow software.

However, reducing the thicknesses of parts to less than $1 \mathrm{~mm}$ is extremely challenging in terms of filling and often leads to an inconsistent distribution of residual stresses, volumetric shrinkages, and warpage in moulded products. Cheng et al. [8] reported the influence of nonuniform stress and shrinkage distributions on warpage deformation. The distribution of residual stresses caused by nonuniform shrinkages 
ultimately generated the most significant warpage problems, particularly in thin-walled parts. Oktem et al. [9] also reported that warpage and shrinkage were the most frequently involved factors in the defects of thin-walled plastic parts in terms of quality. The primary cause of warpage is commonly known to be variations in shrinkage during the injection processing of thin-walled plastic parts.

Subramanian et al. [10] reported that the geometry and mechanical properties of a material also play a critical role in the warpage and that the final warpage of a part strongly depends on its mechanical stiffness, which is a function of the geometrical configuration and of the material's mechanical properties. Azaman et al. [5] determined that the use of shallow, thin-walled parts is preferable for moulding composite materials with lignocellulosic polymers because of the resulting low residual stress and warpage. Shallow, thin-walled parts are more structurally rigid than flat, thin-walled parts, and they can be processed more economically with the use of less material.

The structural rigidity of a thin-walled part is greatly reduced relative to its thick-walled counterpart due to the reduction in its section modulus. The maximum deflection is inversely proportional to the thickness (high deflection occurs with thin parts). Therefore, a potential solution for moulding thin-walled parts is to use a fibre-filled polymer composite, which typically increases the material modulus of the moulded part compared with an unfilled moulded part. Shen et al. [12] performed a numerical analysis on a thinwalled part with a fibre-reinforced thermoplastic material. The MoldFlow software was used for the analysis. Different injection parameters (injection pressure, melt temperature, mould temperature, and injection time), different fibres (short glass and long glass fibres), different fibre ratios ( $40 \%$ and $50 \%)$, and different thickness values $(0.9 \mathrm{~mm}$ and $1 \mathrm{~mm}$ ) were used. The outer shell of a notebook computer was used as the analysis model. Ozcelik and Erzurumlu [13] found that the addition of glass fibre is the most significant factor for PA66 composites in minimising the occurrence of warpage in the moulded part.

Furthermore, Kwiatkowski et al. [14] reported several important factors that influence the deformation of an injection-moulded part, including the structure of the polymer used for the matrix of the composite, the sizes and types of fillers, and the percentage content of the filler. Hakimian and Sulong [15] found that loading glass fibres in the polymer provides a valuable effect on the formation of warpage and the shrinkage properties in moulded microgear parts. These phenomena are due to the orientation of fibres along the direction of the injection flow during the moulding process.

This literature review reveals that limited research has been conducted on the comparison of filled and unfilled thermoplastic composite in moulded thin-walled parts, specifically using neat polypropylene (PP), PP $+10 \mathrm{wt} \%$ glass fibre, and $\mathrm{PP}+50 \mathrm{wt} \%$ wood composite. Hence, this study investigated the processability and identified the interactions among behaviours with respect to residual stresses, volumetric shrinkages, and warpage in moulded thin-walled parts.

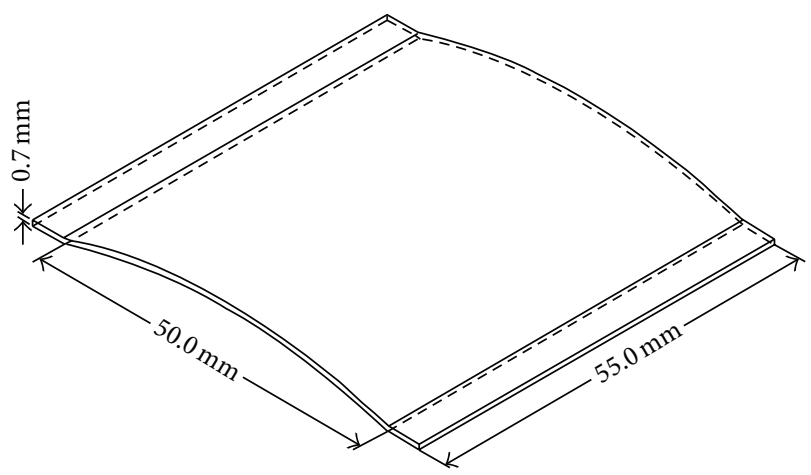

FIgURE 1: A shallow, thin-walled part [5-7].

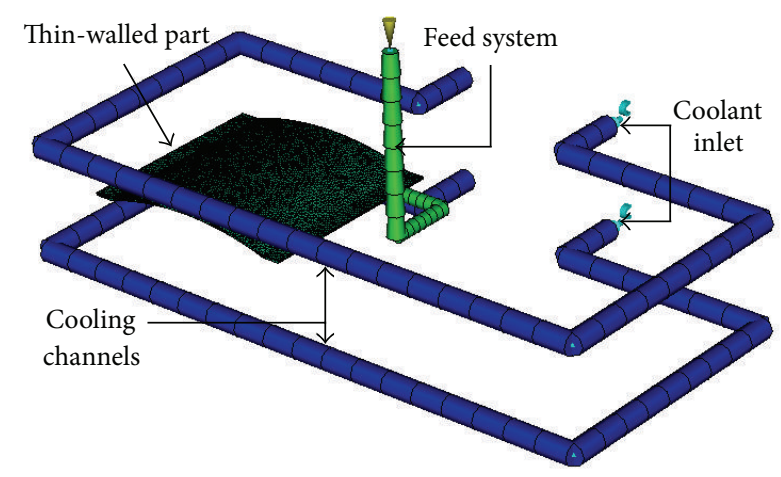

Figure 2: A mesh model for simulation [5-7].

\section{Methodology}

2.1. Part Design. Autodesk Inventor Professional was used to model the moulded thin-walled parts, as shown in Figure 1. A shallow, thin-walled part was created as a $3 \mathrm{D}$ design. The general dimensions of the part were $55 \mathrm{~mm} \times 50 \mathrm{~mm} \times$ $0.7 \mathrm{~mm}$.

2.2. Numerical Simulation. Autodesk MoldFlow Insight was used to simulate and analyse the injection-moulding process. A mesh model was developed, as shown in Figure 2. The injection-moulding machine and the materials used in the simulation adhered to the following specifications: Arburg Allrounder 370c 88-ton injection-moulding machine (screw diameter of $30 \mathrm{~mm}$ ); neat PP from SABIC PP PHC27: SABIC Europe B.V.; PP + $50 \mathrm{wt} \%$ wood composite from Isoform Lip CPCW 50, Isokon; and PP $+10 \mathrm{wt} \%$ glass fibre composite from Polypro R200G: Idemitsu Kosan Co. Ltd. Table 1 presents the specifications of the injection-moulding machine. Table 2 presents the material properties of the PP, PP + $50 \mathrm{wt} \%$ wood composite, and PP $+10 \mathrm{wt} \%$ glass fibre composite. The simulation was performed using a set analysis (fill + cool + fill + pack + warp) for these models. The processing parameters for the simulations are shown in Table 3. 
TABLE 1: Specifications of injection-moulding machine.

\begin{tabular}{lcc}
\hline Parameters & Units & Value \\
\hline Maximum machine injection stroke & $\mathrm{mm}$ & 176.8 \\
Maximum machine injection rate & $\mathrm{cm}^{3} / \mathrm{s}$ & 112.1 \\
Machine screw diameter & $\mathrm{mm}$ & 30 \\
Maximum machine injection pressure & $\mathrm{MPa}$ & 247 \\
Maximum machine clamp force & $\mathrm{MPa}$ & 79.80 \\
\hline
\end{tabular}

2.3. Measurement of In-Cavity Residual Stresses, Volumetric Shrinkage, and Warpage. The results indicate that the incavity residual stresses lie along the first principal direction (plotted at the centre of the surface). Similarly, the volumetric shrinkage and warpage were measured at the centre of the surface.

\section{Results and Discussion}

3.1. Filling Simulation. Figure 3 presents the results of the filling simulations for the materials containing PP without and with fillers. The results of the filling simulations for the thin-walled parts show that $\mathrm{PP}$ is more rapidly filled than that PP with fillers (10 wt $\%$ glass fibre and $50 \mathrm{wt} \%$ wood). The fill time of PP without filler is $1.139 \mathrm{sec}$, whereas for PP $+15 \mathrm{wt} \%$ glass fibre and PP + $50 \mathrm{wt} \%$ wood it is $1.171 \mathrm{sec}$ and $1.269 \mathrm{sec}$, respectively. The properties of the wood fillers, the inconsistency in the shapes of the wood powders, and the possibility of weak interfacial bonding between the polymer and wood fillers cause difficulties for the filler to mix with the melted polymer compared with glass fibre fillers. These findings were similarly reported by Rozman and Wan Daud [16]. However, all materials appear to be ideal for moulding thinwalled parts without the short shot problem.

As shown in Figure 4, the unfilled PP material fills in thinwalled parts faster than the filled PP compound. According to the filling simulation results, with an injection time of $1.1 \mathrm{sec}$, the melted polymer composites containing $\mathrm{PP}+10 \mathrm{wt} \%$ glass fibre and PP + $50 \mathrm{wt} \%$ wood still did not completely fill the cavity of the thin-walled parts. However, the difference in fill time, which is approximately $0.1 \mathrm{sec}$, is sufficiently small and demonstrates that the thin-walled part is capable of being moulded using all three materials. Azaman et al. [5] reported the potential processability of moulded thin-walled parts using lignocellulosic polymer composites in different types of thin-walled part designs, such as shallow and flat structural parts. Shen et al. [12] also conducted numerical analyses on thin-walled parts using different types of fibres (short and long), different fibre ratios ( $40 \mathrm{wt} \%$ and $50 \mathrm{wt} \%$ ), and different thickness values $(0.9 \mathrm{~mm}$ and $1 \mathrm{~mm})$.

3.2. In-Cavity Residual Stresses Distribution. The in-cavity residual stresses in the first principal direction describe the inherent stress along the orientation direction before a part is ejected from a mould. These residual stresses occur inside a mould and will be altered after the part is ejected. However, the results obtained in this study are sufficient for relating and describing the quality of the final part in terms of the predicted shrinkage and warpage $[17,18]$. In addition, Altan and Yurci [19] noted that the critical stresses should be determined at or near the surface region because high tensile stresses near the region of the injection-moulded parts are known to result in environmental stress cracking and to be sensitive to chemical diffusion. However, the formation of residual stresses must be taken into account to distinguish the formation of residual stresses among unfilled and filled reinforced polymer composites.

Figure 5 presents the simulated residual stresses in the thickness direction at the centre of the thin-walled part surface for all three materials (i.e., PP, PP $+50 \mathrm{wt} \%$ wood, and PP +10 wt $\%$ glass fibre). The thickness in the plot was normalised from -1 to 1 according to the core and cavity sides of the mould. The maximum residual tensile stresses occur near the wall in the core and cavity mould. The maximum residual stresses decrease when approaching the subsurface, at approximately $0.175 \mathrm{~mm}$. However, the core region exhibits a parabolic tensile peak near a thickness of $0.35 \mathrm{~mm}$ for both sides of the parts. The distribution pattern of the residual stresses through the thickness of the part is consistent with the patterns reported in previous studies [20-22]; the only difference exists at the subsurface region where the residual compressive stress is normally formed. This difference occurred because these simulation results are based on the residual stress formed before ejection, which means that the results are almost always positive because the part is still constrained within the mould.

The widths of the core regions in the parabolic profile of the residual stresses on thin-walled parts for PP polymer wider than fibre/filler-reinforced polymers follow the sequence PP $+10 \mathrm{wt} \%$ glass fibre and $\mathrm{PP}+50 \mathrm{wt} \%$ wood. This residual stress distribution profile is caused by thermal contraction (i.e., sources from the melt temperature, mould temperature, and shearing polymer melt), affecting the crystallisation process. This is explained by the different values of the coefficient of thermal expansion (CTE) of the compound, which influences the level of inner stresses in the crystallisation process, as shown in Table 2. The high CTE value of the compound is able to increase the crystallisation time, which consequently induces slower crystallisation with lower stresses that become frozen with sufficient relaxation. Ziran et al. [23] also reported that the crystallinity process, coefficient of thermal expansion, and elastic modulus have important effects on the development of internal stresses. With decreasing crystallinity, the internal stresses diminish.

As shown in Figure 5, the residual stress in the reinforced polymer composite is greater than that in the unfilled polymer. For filler-reinforced polymers, the orientation of the fillers has a greater effect than does the molecular orientation (neat polymer resin without fillers) [24]. Thus, the orientation of the fillers influenced the distribution of residual stresses in the through-thickness direction along the part surface. The results revealed that the residual tensile stress formed by PP + $50 \mathrm{wt} \%$ wood is approximately $25 \mathrm{MPa}$ higher than the values of $20.2 \mathrm{MPa}$ and 17.2 MPa for PP + $10 \mathrm{wt} \%$ glass fibre and PP, respectively, which occurred near the wall at both sides of the parts. However, the residual tensile stress of PP $+50 \mathrm{wt} \%$ wood was low $(15.8 \mathrm{MPa})$ compared to that of PP $+10 \mathrm{wt} \%$ 
TABLE 2: The material properties of PP, PP + $50 \mathrm{wt} \%$ wood, and PP $+10 \mathrm{wt} \%$ glass fibre.

\begin{tabular}{lccc}
\hline & PP & PP + 50 wt\% wood & PP + 10 wt\% glass fibre \\
\hline Trade name & SABIC PP PHC27 & Isoform Lip CPCW 50 & Polypro R200G \\
Filler content (wt\%) & 0 & 50 & 10 \\
Material structure & Semicrystalline & Semicrystalline & Semicrystalline \\
Coefficient of thermal expansion, CTE $\left(1 /{ }^{\circ} \mathrm{C}\right)$ & $1.45 E-4$ & $6.81 E-5$ & $5.43 E-5$ \\
\hline
\end{tabular}

TABLE 3: The processing parameter settings.

\begin{tabular}{|c|c|c|c|}
\hline & $\mathrm{PP}$ & $\begin{array}{l}\mathrm{PP}+50 \mathrm{wt} \% \\
\text { wood }\end{array}$ & $\begin{array}{l}\mathrm{PP}+10 \mathrm{wt} \% \\
\text { glass fibre }\end{array}$ \\
\hline Melt temperature $\left({ }^{\circ} \mathrm{C}\right)$ & 230 & 185 & 230 \\
\hline Injection time (sec) & 1 & 1 & 1 \\
\hline $\begin{array}{l}\text { Mould temperature } \\
\left({ }^{\circ} \mathrm{C}\right)\end{array}$ & 40 & 45 & 50 \\
\hline Cooling time (sec) & 20 & 20 & 20 \\
\hline $\begin{array}{l}\text { Packing pressure } \\
(\mathrm{MPa})\end{array}$ & $0.8 P_{\text {inject }}$ & $0.8 P_{\text {inject }}$ & $0.8 P_{\text {inject }}$ \\
\hline Packing time (sec) & 10 & 10 & 10 \\
\hline
\end{tabular}

Remarks: parameter setting refers to material database recommendation [11].

glass fibre (17.2 $\mathrm{MPa})$ near the core region along the thickness direction, while the pure PP is $14.0 \mathrm{MPa}$ lower than both of the filler-reinforced polymer composites.

Due to the characteristic of the chain structure of the polymer material, its molecular chains are easily oriented as a result of flow shear stress during the filling process and thermal contraction after the filling process. Therefore, for the unfilled polymer, PP exhibits the lowest residual stresses, which occurred near both the walls and core region of the thin-walled part. In contrast, the orientation of molecular chains in the filler-reinforced polymer in the through-thickness direction can be quite complex. The orientations of the fillers significantly influence the formation of residual stresses inside the moulded part. In particular, discussing the orientation of the particulate powder about the PP + $50 \mathrm{wt} \%$ wood fibre orientation compared to $\mathrm{PP}+10 \mathrm{wt} \%$ glass fibre is more complicated. During the cooling phase, the possibility of wood powder orientation occurred with a random arrangement. According to Khalina et al. [25], the orientation distribution of the particulate powder is not the same as the arrangement of the fibre orientation in the moulded part, but the powder form dispersed more uniformly, as reported by Rozman et al. [26]. The simulation results show the expected high orientation of wood near the wall surface due to the value of the residual tensile stresses being high, and the opposite occurs in the core regions.

Similarly, the glass fibres oriented inside the polymer composite melt in the moulded thin-walled part during the crystallisation process. However, the arrangement of the oriented glass fibres differs, with the fibres on the wall surface being scattered parallel to the flow direction, whereas the orientation in the core regions is perpendicular to the flow direction. The arrangement of this orientation is more easily explained with the statement from $\mathrm{Xu}$ and $\mathrm{Yu}$ [24]. During the cooling of the melt, the chains with frozen orientations always have a tendency to develop from a high energy state to lower energy state. This means that recrystallisation occurred, which will lead to an inconsistent alignment direction and further generate internal stresses. Therefore, filled polymers cause the melt flow rate to decrease and the cooling rate to increase because glass fibres impart a lower coefficient of thermal expansion to the reinforcement relative to the surrounding polymer [27]. Then, the frozen in orientation will be more critical; thus, the residual stress of the moulded part will be larger.

3.3. Volumetric Shrinkage Simulation. Figure 6 shows the value of percentage volumetric shrinkage change during the solidification process between the cavity and core sides, which was measured at the centre of the thin-walled part surface. The value of the volumetric shrinkage change (\%VS $\max -\% \mathrm{VS} \min )$ of PP $+10 \mathrm{wt} \%$ glass fibre was low $(4.32 \%)$ compared to PP $+50 \mathrm{wt} \%$ wood and $\mathrm{PP}(4.7 \%$ and $6.48 \%$, resp.).

Unfilled polymers, such as PP, exhibit isotropic linear shrinkage behaviour, meaning that the properties of the moulded part are similar, following the direction of flow, either parallel or perpendicular, as well as across the thickness. It is widely accepted that semicrystalline plastics shrink more than amorphous ones because of the closer packing in the crystalline structure [28]. In detail, during the filling stage, semicrystalline polymers such as PP can exhibit significantly higher shrinkage rates. There is a significant change in the specific volume when the polymer transitions from a closely packed semicrystalline solid to a loosely packed amorphous melt. This increase in the specific volume can give rise to significant volumetric shrinkage and high shrinkage rates. Moulding applications with such high shrinkage rates tend to be more difficult to control to tight tolerances due to their sensitivity to the processing conditions.

In contrast, glass/wood-filled polymer composites can be used to influence the amount of shrinkage that a material exhibits for thin-walled part moulding. The presence of these fillers is capable of changing the material properties, which primarily depend on the flow direction. Kwiatkowski et al. [14] reported that one factor that influences the shrinkage deformation is the percentage content of the filler. The shrinkage deformation of moulded parts is influenced by the difference in fibre orientation either parallel or transverse to the polymer flow direction, which resulted in the shrinkage measured parallel being $50 \%$ greater than that in the transverse direction [14].

For anisotropic materials, the glass or wood fillers can become highly aligned in the flow field during the filling, 


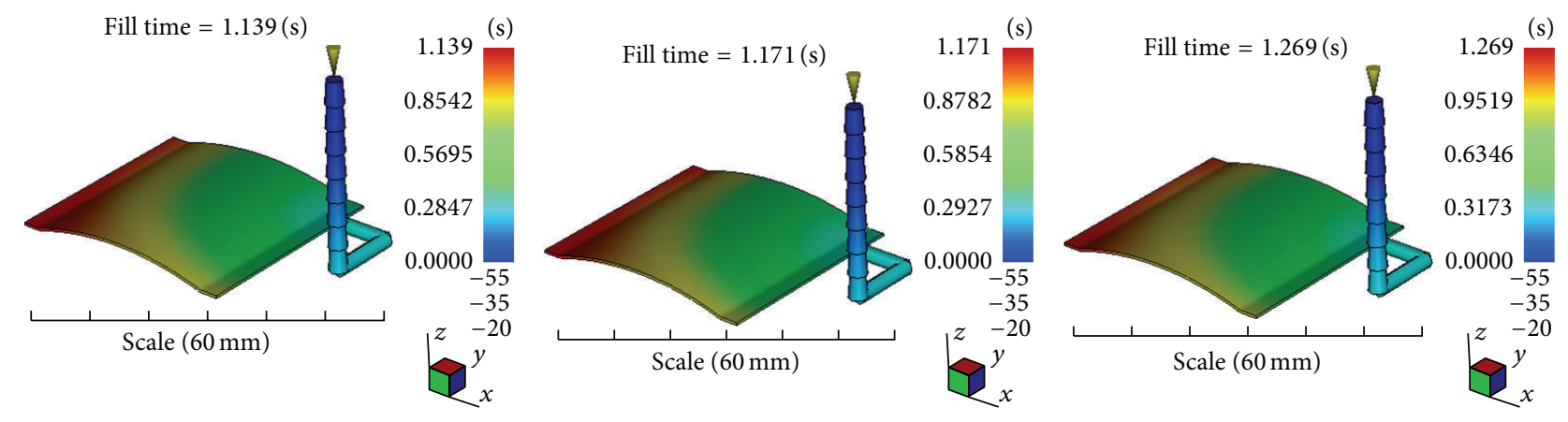

(a)

(b)

(c)

Figure 3: Fill times for (a) PP, (b) PP + 10 wt $\%$ glass fibre, and (c) PP +50 wt $\%$ wood.
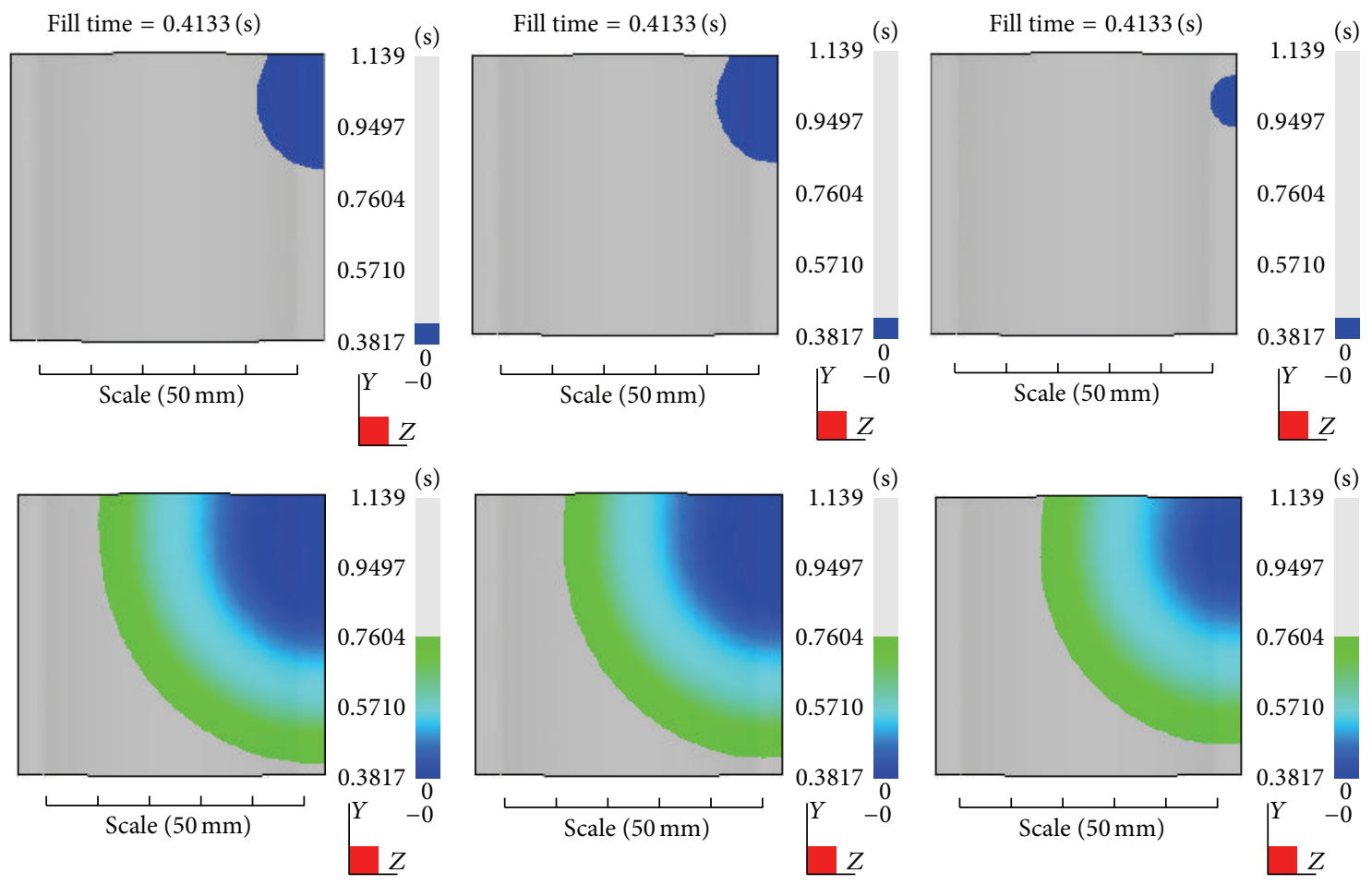

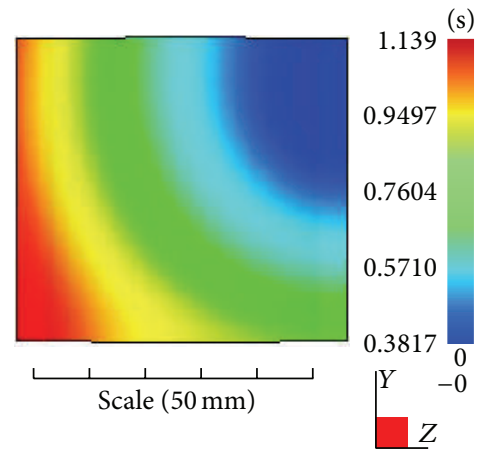

(a)

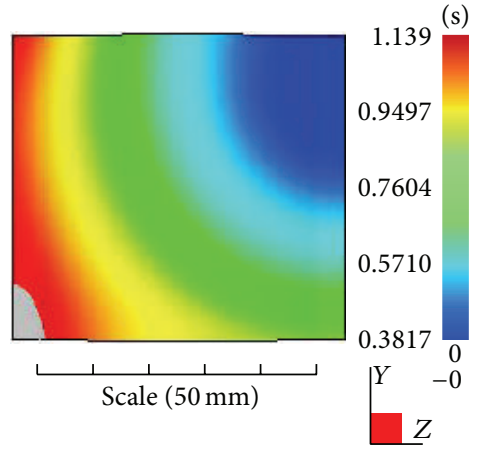

(b)

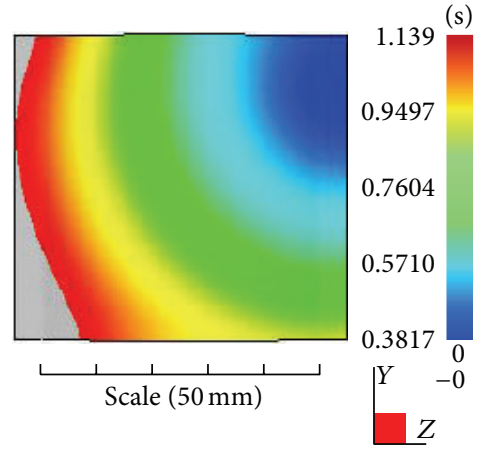

(c)

Figure 4: Filling phase for (a) PP, (b) PP + 10 wt $\%$ glass fibre, and (c) PP + 50 wt $\%$ wood. 


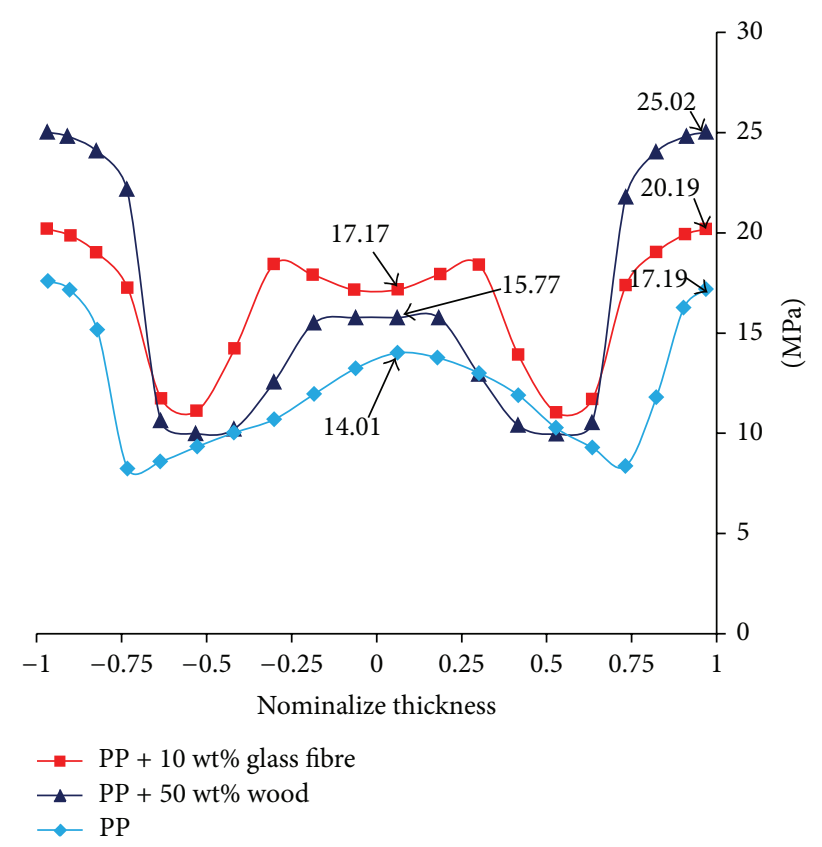

FIGURE 5: The residual tensile stress distribution occurs at the centre of the surface of the thin-walled parts for PP, PP + 10 wt\% glass fibre, and PP + 50 wt $\%$ wood.

packing, and cooling stages. The orientation of the glass or wood filler through the thickness can be quite complex depending on the flow direction, which influences the determination of the arrangement of filler: either random, parallel, or perpendicular. In addition, anisotropic materials exhibit different properties in their principal shrinkage directions compared to isotropic materials.

The results show that the glass fibre-filled polymer composite exhibits less shrinkage changes. Because glass fibre has a lower coefficient of thermal expansion, the polymer compound also tends to have lower shrinkage as a result of the glass fibre having predominant alignment in the parallel direction that is dependent on the flow direction between wall surface and core regions. Filled polymer composites, such as $\mathrm{PP}+10 \mathrm{wt} \%$ glass fibre and $\mathrm{PP}+50 \mathrm{wt} \%$ wood, possess lower coefficients of thermal expansion, which will be reflected in lower changes in volumetric shrinkages during the solidification process compared to the PP polymer. Therefore, the addition of one or more fillers to a neat resin can be used to reduce the volumetric shrinkages of polymers and to increase the dimensions of the moulded parts, particularly in moulded thin-walled parts.

3.4. Warpage Simulation. The structural rigidity of a thinwalled part is greatly reduced due to the reduction in the section modulus. There are several potential solutions to increase the structural rigidity, such as using a glass- or woodreinforced polymer compound, determining behaviour of residual stresses and volumetric shrinkage, optimising the moulding parameters, and emphasising the design process. When a moulded part distorts or deflects out of plane, warpage is occurring. In reality, the warpage problem can be

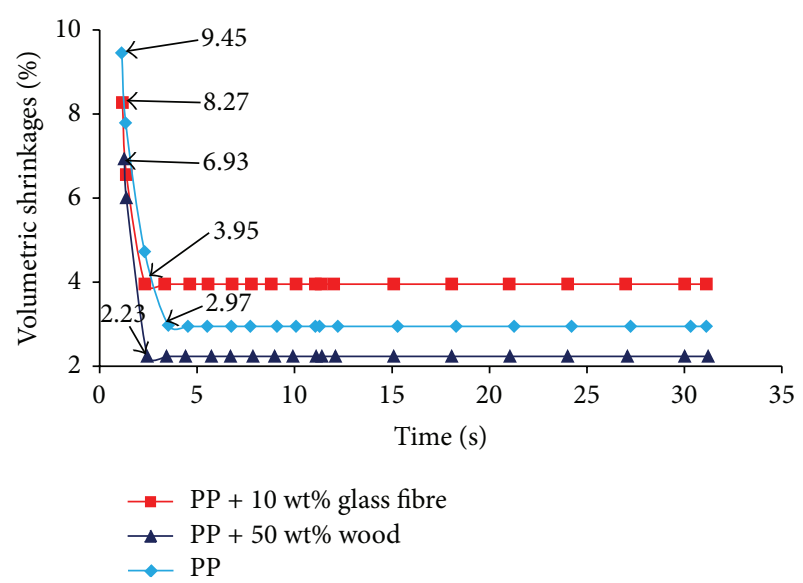

FIGURE 6: The residual volumetric shrinkages distribution occurs at the centre of the surface of the thin-walled parts for PP, PP + $10 \mathrm{wt} \%$ glass fibre, and PP $+50 \mathrm{wt} \%$ wood.

more difficult to predict and correct. Timothy [29] noted that the rigidity of a thin-walled part will still depend on the wall thickness and design specification, both of which dominate over the effect of fibre reinforcement or the resin used. Nevertheless, the results show that the warpage problem has a dependence on the residual stresses and volumetric shrinkage distribution behaviours, particularly for thin-walled parts.

The results in Figure 7 show that the maximum warpage on a thin-walled part is $0.43 \mathrm{~mm}$ for $\mathrm{PP}+50 \mathrm{wt} \%$ wood, which is higher than PP and PP $+10 \mathrm{wt} \%$ glass fibre $(0.36 \mathrm{~mm}$ and $0.29 \mathrm{~mm}$, resp.). However, this high deflection resulting from PP $+50 \mathrm{wt} \%$ wood does not occur in the critical area of the thin-walled part compared with $\mathrm{PP}+10 \mathrm{wt} \%$ glass fibre, as shown in Figure 7 . Taking into account the structural rigidity of thin-walled parts, the high deflection should be prevented from forming along the curved surface of the part.

Visualisation of the simulation results shows that the minimum warpage distribution appears more uniform for the moulded thin-walled part using PP + $50 \mathrm{wt} \%$ wood than for that using PP $+10 \mathrm{wt} \%$ glass fibre and PP. The filler with fine powder form type results in dispersion with uniformity in moulding a thin-walled part. This was consistent with the finding of Rozman et al. [26], in which the enforcement of natural ingredients in fine powder form type can provide more uniform dispersion in a polymer matrix and provide an improvement in mechanical properties compared with the filler in the coarse fibre form type. Furthermore, the fillers materials in the coarse fibre form type tend to cluster or aggregate, specifically in moulded thin-walled parts.

The discussion will be focused in terms of improving the structural rigidity of thin-walled parts. The results reveal that the warpage at the midpoint of the part surface injected using PP + $50 \mathrm{wt} \%$ wood is $0.04 \mathrm{~mm}$ lower than that value of $0.08 \mathrm{~mm}$ using $\mathrm{PP}+10 \mathrm{wt} \%$ glass fibre. This phenomenon can be attributed to changes in the distribution of residual stresses that occur in the core regions: $\mathrm{PP}+50 \mathrm{wt} \%$ wood is $15.77 \mathrm{MPa}$ lower than $\mathrm{PP}+10 \mathrm{wt} \%$ glass fibre $(17.17 \mathrm{MPa})$. Furthermore, the volumetric shrinkages of PP $+10 \mathrm{wt} \%$ of glass fibre are 


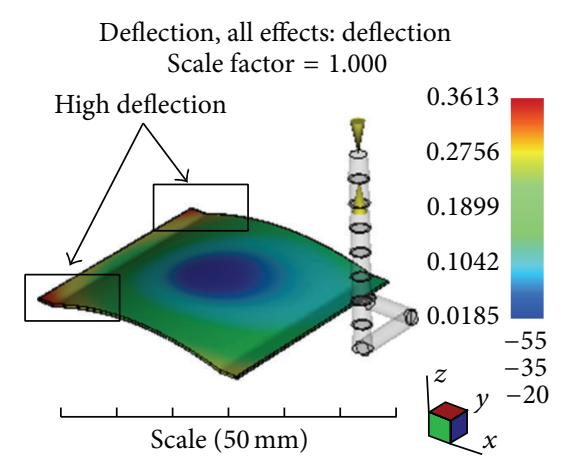

(a)

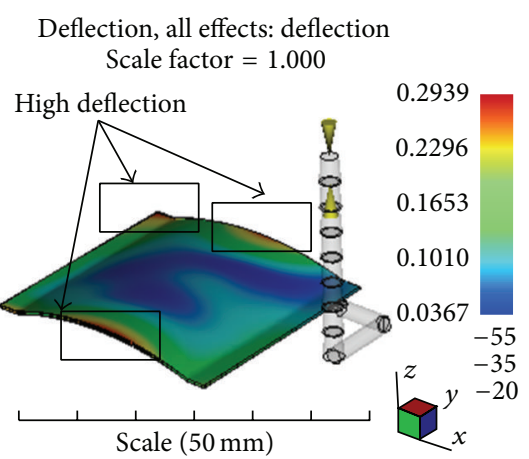

(b)

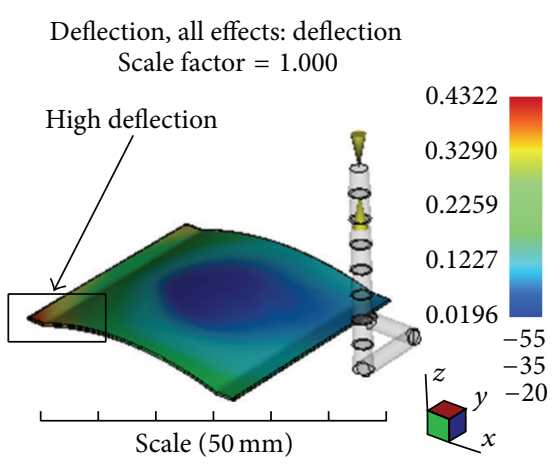

(c)

Figure 7: The distribution of warpages on the thin-walled parts for (a) PP, (b) PP $+10 \mathrm{wt} \%$ glass fibre, and (c) PP $+50 \mathrm{wt} \%$ wood.

observed to begin to become uniform at 3.95\% from $2.3 \mathrm{sec}$, which is faster than that of PP $+50 \mathrm{wt} \%$ wood at $2.23 \%$ from $2.5 \mathrm{sec}$ take longer or more time. More time required for the solidification process tends to minimise warpages occurring at the regions. Therefore, the results of constant volumetric shrinkage for $\mathrm{PP}+50 \mathrm{wt} \%$ wood are lower than $\mathrm{PP}+10 \mathrm{wt} \%$ glass fibre, which significantly affect the value of warpage at that location.

\section{Conclusions}

In conclusion, this study shows that unfilled and filled polymer PP composites are suitable for moulding thin-walled parts. The PP without filler filled the fastest, with a fill time of $1.139 \mathrm{sec}$. In contrast, the residual stress results show that the polymer composite has higher stress than the unfilled one. The residual tensile stress formed by PP $+50 \mathrm{wt} \%$ wood is approximately $25 \mathrm{MPa}$ higher than the values of $20.2 \mathrm{MPa}$ and 17.2 $\mathrm{MPa}$ for $\mathrm{PP}+10 \mathrm{wt} \%$ glass fibre and PP, respectively, which occurred near the wall at both sides of the parts. However, the residual tensile stress of PP $+50 \mathrm{wt} \%$ wood was low $(15.8 \mathrm{MPa})$ compared to that of $\mathrm{PP}+10 \mathrm{wt} \%$ glass fibre (17.2 MPa) near the core of the thickness direction. Furthermore, some fillers in PP can be used to influence the amount of shrinkage that a material exhibits for the moulding of thinwalled parts. The value of the volumetric shrinkage change (\%VS max - \%VS min) of PP $+10 \mathrm{wt} \%$ of glass fibre was low $(4.32 \%)$ compared to those of PP $+50 \mathrm{wt} \%$ wood and PP ( $4.7 \%$ and $6.48 \%$, resp.). Visualisation of the simulation results revealed that the minimum warpage distribution appears to be more uniform for moulded thin-walled parts using PP + $50 \mathrm{wt} \%$ wood than for those using PP + $10 \mathrm{wt} \%$ glass fibre and PP. The high deflection resulting from PP + $50 \mathrm{wt} \%$ wood does not occur in the critical area of the thinwalled part compared with PP $+10 \mathrm{wt} \%$ glass fibre. In addition, the results revealed that the warpage at the midpoint of the part surface injected using PP + $50 \mathrm{wt} \%$ wood is $0.04 \mathrm{~mm}$ lower than the value of 0.08 when using $\mathrm{PP}+10 \mathrm{wt} \%$ glass fibre. Finally, the results revealed that the existing warpage has a close relationship with the formation of residual stresses and volumetric shrinkages in moulded thin-walled parts.

\section{Conflict of Interests}

The authors declare that there is no conflict of interests regarding the publication of this paper.

\section{Acknowledgment}

The authors would like to thank Universiti Putra Malaysia for the financial support through the Research University Grant Scheme (Project no. RUGS/05-02-12-1917RU).

\section{References}

[1] S. Chris, "Roctool claims thin wall gains in electronics," in Injection World, p. 47, Applied Market Information, 2014.

[2] S. Chris, "Xiaomi adopts LNP compounds for ultra-slim smartphone," in Injection World, p. 46, Applied Market Information, 2014.

[3] Y.-K. Shen, C.-W. Wu, Y.-F. Yu, and H.-W. Chung, "Analysis for optimal gate design of thin-walled injection molding," International Communications in Heat and Mass Transfer, vol. 35, no. 6, pp. 728-734, 2008.

[4] B. Ozcelik and I. Sonat, "Warpage and structural analysis of thin shell plastic in the plastic injection molding," Materials and Design, vol. 30, no. 2, pp. 367-375, 2009.

[5] M. D. Azaman, S. M. Sapuan, S. Sulaiman, E. S. Zainudin, and K. Abdan, "An investigation of the processability of natural fibre reinforced polymer composites on shallow and flat thin-walled parts by injection moulding process," Materials and Design, vol. 50, pp. 451-456, 2013.

[6] M. D. Azaman, S. M. Sapuan, S. Sulaiman, E. S. Zainudin, and A. Khalina, "Shrinkages and warpage in the processability of wood-filled polypropylene composite thin-walled parts formed by injection molding," Materials and Design, vol. 52, pp. 10181026, 2013.

[7] M. D. Azaman, S. M. Sapuan, S. Sulaiman, E. S. Zainudin, and A. Khalina, "Numerical simulation analysis of the in-cavity residual stress distribution of lignocellulosic (wood) polymer composites used in shallow thin-walled parts formed by the injection moulding process," Materials \& Design, vol. 55, pp. 381-386, 2014.

[8] X. M. Cheng, L. Zhou, N. Y. Sheng, and Y. D. Wu, "Injection molding and warpage of thin-walled parts based on simulated 
deformation," in PRoceedings of the International Conference on Computational Intelligence and Software Engineering (CiSE '09), pp. 1-4, Wuhan, China, December 2009.

[9] H. Oktem, T. Erzurumlu, and I. Uzman, "Application of Taguchi optimization technique in determining plastic injection molding process parameters for a thin-shell part," Materials and Design, vol. 28, no. 4, pp. 1271-1278, 2007.

[10] N. R. Subramanian, L. Tingyu, and Y. A. Seng, "Optimizing warpage analysis for an optical housing," Mechatronics, vol. 15, no. 1, pp. 111-127, 2005.

[11] Moldflow Thermoplastic Database, Autodesk Moldflow Insight, 2011.

[12] Y. K. Shen, P. H. Yeh, and J. S. Wu, "Numerical simulation for thin wall injection molding of fiber-reinforced thermoplastics," International Communications in Heat and Mass Transfer, vol. 28, no. 8, pp. 1034-1042, 2001.

[13] B. Ozcelik and T. Erzurumlu, "Comparison of the warpage optimization in the plastic injection molding using ANOVA, neural network model and genetic algorithm," Journal of Materials Processing Technology, vol. 171, no. 3, pp. 437-445, 2006.

[14] D. Kwiatkowski, A. Gnatowski, and J. Nabialek, "Numerical analysis of residual stresses and deformation of injection moulded parts manufactured from polymeric composite with different processing conditions," Kompozyty, vol. 4, pp. 294298, 2011.

[15] E. Hakimian and A. B. Sulong, "Analysis of warpage and shrinkage properties of injection-molded micro gears polymer composites using numerical simulations assisted by the Taguchi method," Materials and Design, vol. 42, pp. 62-71, 2012.

[16] H. D. Rozman and W. R. Wan Daud, "Developments of oil palm based lignocellulosic polymer blend," in Polymer Blends (719), G. O. Shonaike and G. P. Simon, Eds., Marcel Dekker, New York, NY, USA, 2000.

[17] "In-cavity residual stresses in first principal direction," Autodesk Moldflow Insight Help, Autodesk Moldflow Insight, 2011.

[18] A. Nita and E. Oanta, "Improving the quality of the molded polymeric parts by reducing the residual stress," in Proceedings of the 2nd International Conference on Manufacturing Engineering, Quality and Production Systems (MEQAPS '10), pp. 77-82, Constantza, Romania, September 2010.

[19] M. Altan and M. E. Yurci, "Optimization of residual stresses in the surface regions of injection moldings," Polymer-Plastics Technology and Engineering, vol. 49, no. 1, pp. 32-37, 2010.

[20] S. K. Kim, S. W. Lee, and J. R. Youn, "Measurement of residual stresses in injection molded short fiber composites considering anisotropy and modulus variation," Korea-Australia Rheology Journal, vol. 14, no. 3, pp. 107-114, 2002.

[21] H. Zhou, G. Xi, and F. Liu, "Residual stress simulation of injection molding," Journal of Materials Engineering and Performance, vol. 17, no. 3, pp. 422-427, 2008.

[22] T. Azdast, A. H. Behravesh, K. Mazaheri, and M. M. Darvishi, "Numerical simulation and experimental validation of residual stress induced constrained shrinkage of injection molded parts," Polimery, vol. 53, no. 4, pp. 304-310, 2008.

[23] L. Ziran, C. Gongxuan, and W. Haihong, "The simulation of internal stresses of injection molded crystalline polymers during cooling stage," in Proceedings of the 1st International Conference on Computing Control and Industrial Engineering (CCIE '10), pp. 136-140, June 2010.
[24] Q. J. Xu and S. W. Yu, "Calculation of residual stress in injection molded production molded products for polymer materials," Chinese Journal of Theoretical and Applied Mechanics, vol. 30, pp. 157-167, 1998.

[25] A. Khalina, H. Jalaluddin, P. A. Martin, Z. M. D. Khairul, J. Rimfiel, and I. Nor Azowa, "Mechanical and rheology properties of injection moulded short oil palm fibre reinforced polymer composite," in Research on Natural Fibre Reinforced Polymer Composite, S. M. Sapuan, Ed., pp. 109-125, Universiti Putra Malaysia Publishers, 2009.

[26] H. D. Rozman, G. B. Peng, and Z. A. M. Ishak, “The effect of compounding techniques on the mechanical properties of oil palm empty fruit bunch-polypropylene composites," Journal of Applied Polymer Science, vol. 70, no. 13, pp. 2647-2655, 1998.

[27] E. J. Fahy, "Modeling warpage in reinforced polymer disks," Polymer Engineering and Science, vol. 38, no. 7, pp. 1072-1084, 1998.

[28] R. A. Malloy, Plastic Part Design for Injection Molding-An Introduction, Hanser, New York, NY, USA, 1994.

[29] A. P. Timothy, "10 common pitfalls in thin-wall plastic part design," in Speciallize Molding Techniques, H. P. Heim and H. Potente, Eds., pp. 107-112, Plastic Design Library, Norwich, NY, USA, 2001. 

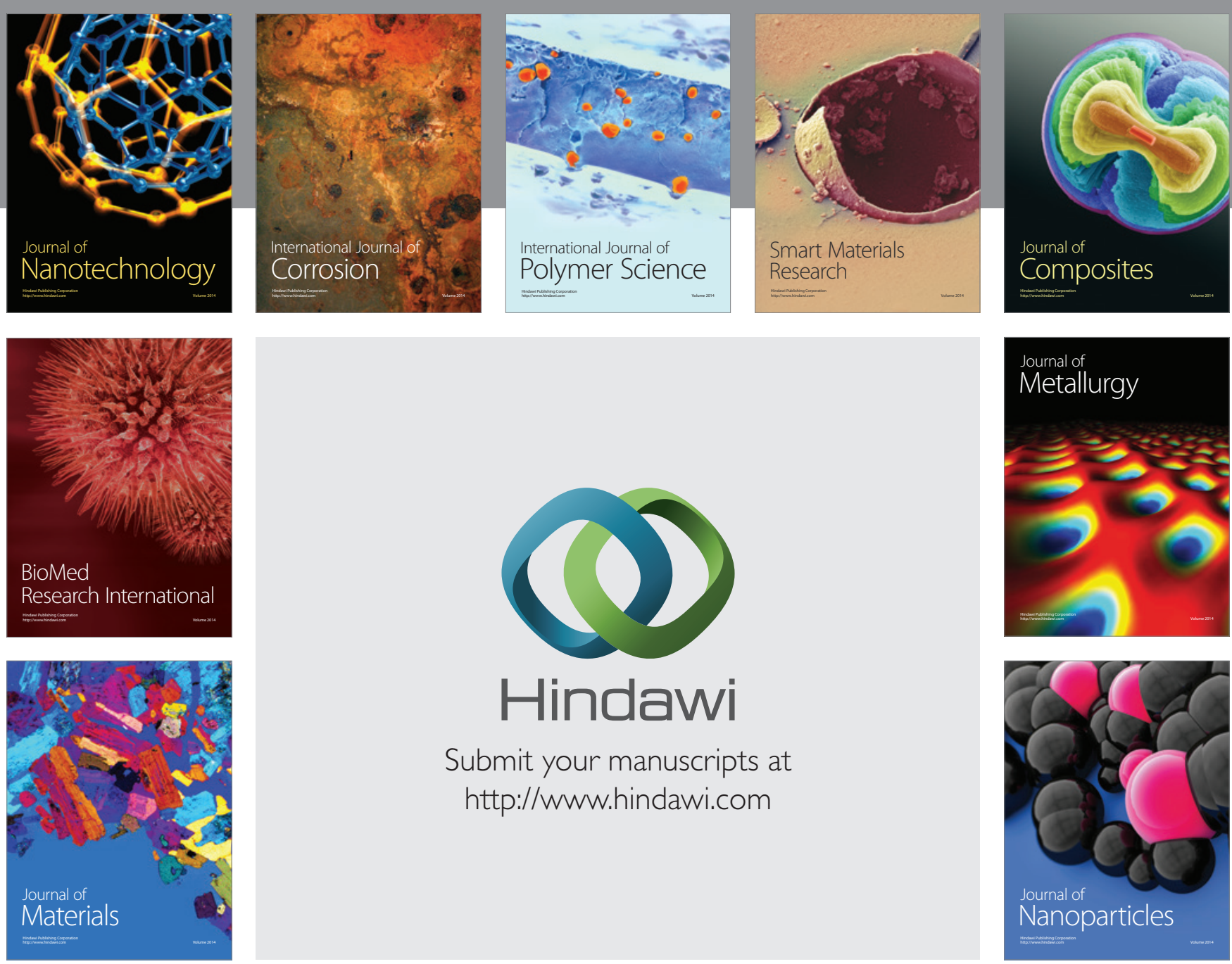

Submit your manuscripts at http://www.hindawi.com
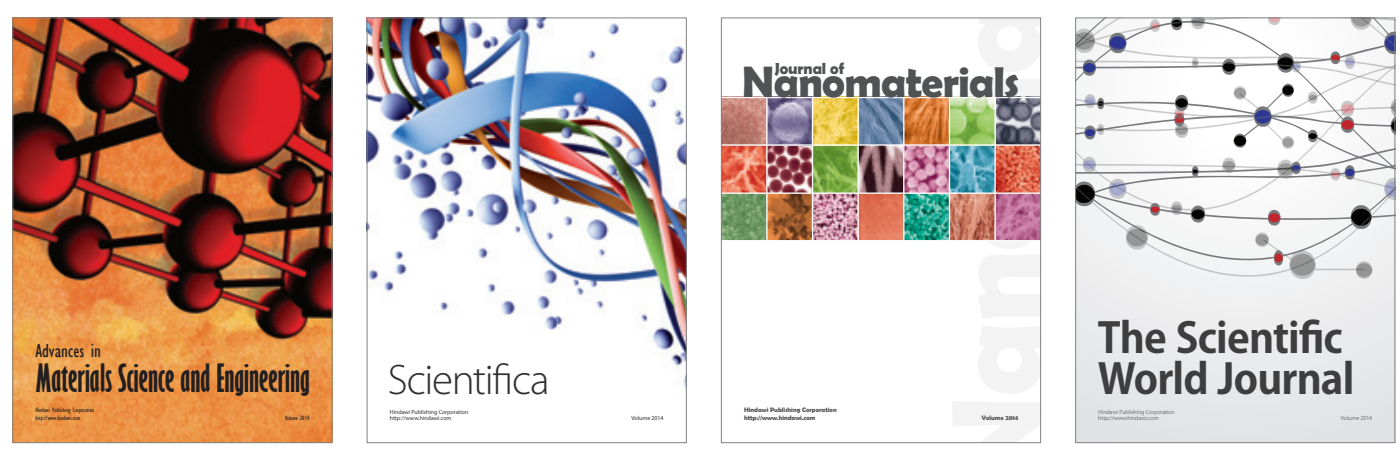

\section{The Scientific World Journal}
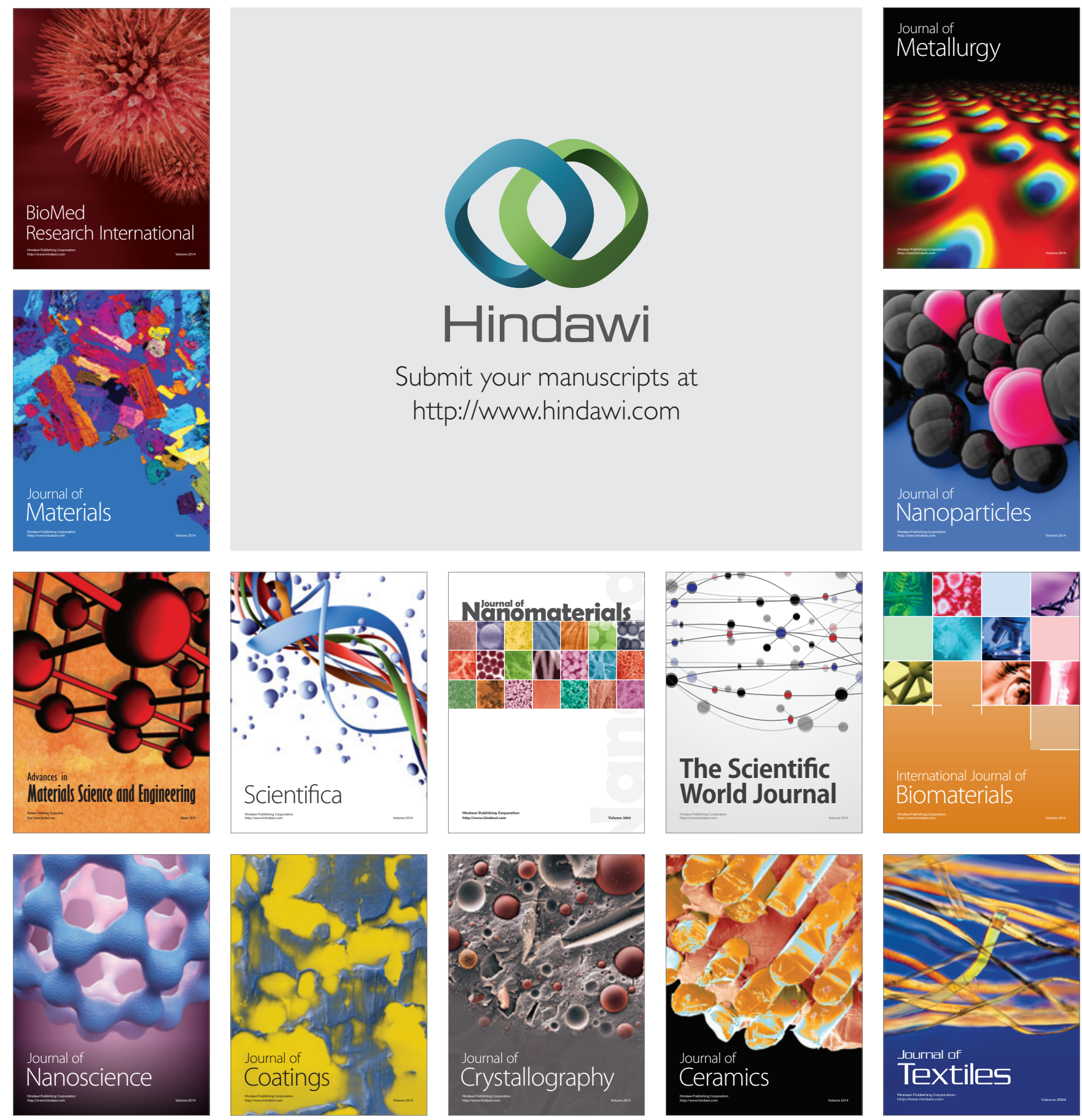